\title{
Pensar desde y con los cuerpos: aproximaciones a una sociología del cuerpo
}

Santiago Caneda Lowry Universidad Nacional de Educación a Distancia (UNED) santicaneda@gmail.com

\section{Introducción}

El objetivo del presente trabajo es ofrecer los aspectos fundamentales para una comprensión global -aunque superficial- de la sociología del cuerpo, así como sus estrategias y potencialidades epistemológicas, posibilidad que encuentra su momentum en nuestra actualidad, cargada de adjetivos y coletillas de entre los que elegimos, hoy, su carácter global, de proliferación de prácticas (disciplinarias) de consumo, orientadas, en su esencia -eso sostenemos- hacia la corporalidad, en la medida en que, por este camino, se encuentra un acceso casi inmediato a la construcción de la subjetividad -si es que algo como esto, aún hoy, es objeto de nuestras ideas-. Presentamos, pues, al cuerpo como una herramienta epistemológica, de forma que quede expuesto este acceso rápido y su funcionamiento, el de la sociedad de consumo.

Expondré los desarrollos teóricos ineludibles para alcanzar esa compresión, tomando como punto de partida la teoría social clásica y su casi nula atención a la condición corporal de la humanidad, hasta el interaccionismo simbólico. 
A continuación, centraremos nuestra atención en las claves históricas y teóricas que explican el auge de la teoría social consciente de nuestra condición corporal; como pueden ser los revolucionarios avances en medicina o la liberación sexual, o las teorías de autores ya clásicos como Marcel Mauss, Michel Foucault o Pierre Bourdieu, entre otros. El artículo encuentra su final en unas conclusiones generales que intentan que ese final no sea tal, llevando más allá lo expuesto, tanto en pos de esta llamada de atención sobre la utilidad de considerar los cuerpos, como de una llamada de atención más importante, sobre nuestros propios cuerpos.

Desde Marx hasta Goffman:

El cuerpo y la teoría social clásica

La cuestión social no es sólo una cuestión moral, sino también una cuestión nasal.

Georg Simmel

Lo "más cercano" se halla en lo que está alejado dentro de una posibilidad media de alcanzarlo, cogerlo, verlo. [...] Al andar se lo toca a cada paso, y parece ser lo más cercano y más real de todo lo "a la mano", desplegándose, por decirlo así, en contacto directo con determinadas partes del cuerpo, las plantas de los pies. Y sin embargo, está mucho más alejado que el conocido con quien al andar así se tropieza "en la calle" a la "distancia" de veinte pasos.

Martin Heidegger, Ser y tiempo, § 23. 
No podríamos alcanzar esta comprensión, como dijimos, sin revisar, siquiera brevemente, la atención prestada a la condición corporal de la existencia humana en la tradición teórica. Quitando algunas excepciones -y sin necesidad de llegar hasta Platón-, la teoría sociológica clásica, como podremos ver, no guarda un tratamiento manifiesto, ni mucho menos profundo, de la corporalidad humana (ver Turner, 1994: 11-39; Le Breton, 2011). Esto significa que, desde un punto de vista general, el humano sujeto del pensamiento sociológico no sólo es representado como una conciencia sin cuerpo, sino que se lo piensa y desarrolla a partir de tal esquema (con la consiguiente expulsión y condena de todo avance en esta línea, fallo que va más allá del rechazo de los conocimientos en materia de fisiología). En este primer apartado expondremos esa "censura" en la teoría social, de forma que podamos atisbar ya los balbuceos de una respuesta a la pregunta que guía la sociología del cuerpo: ¿cómo es, cómo se hace notar, el cuerpo, la condición corporal del socius de la sociología?

Tomemos a Marx, al de los Manuscritos de economía y filosofía, como una primera orientación y, también, como una primera excepción dentro del canon teórico de la sociología y su (falta de) atención al cuerpo. Uno de los objetivos centrales de estos manuscritos es la crítica al idealismo hegeliano de su época, así como al materialismo de Feuerbach, en un doble gesto que deviene un único movimiento, y que consiste en "curar" a ambas partes de lo que carecen entre sí. De tal forma, el autor de una tesis sobre Demócrito y Epicuro, cura al materialismo de su época de la falta de historicismo ${ }^{1}$ que él le

1 “En la medida en que Feuerbach es materialista, no aparece en él la historia, y en la medida en que toma en consideración la historia, no es materialista" (Engels, F. y Marx, K., 1994: 47). 
acusa, y al idealismo de su incoherente falta de materialidad. Tal gesto, como sabemos, carga el nombre de materialismo dialéctico, pero no es necesario entrar aquí en su desarrollo; podemos quedarnos, sencillamente, con algunos apuntes -incluso biográficos-, que nos acerquen a comprender la llamada de atención que, en su momento, hizo Marx al idealismo “etéreo", que no es otra que sobre la condición corporal humana.

Nuestro primer apunte, de carácter biográfico, nos lleva a la vida del joven Marx, a uno de sus primeros empleos, como redactor jefe de un pequeño periódico cercano a la izquierda hegeliana ${ }^{2}$. Este empleo requería de él un contacto cercano con la miseria real de su época, con la materialidad más mísera de los hechos sociales. Situémonos, imaginemos que, como hegelianos de izquierda, orientados hacia aquel espíritu absoluto y liberador, nos invade el olor - por usar las palabras de Sim$\mathrm{mel}^{3}$ - de la miseria humana y, por tanto, de la miseria del pensamiento, incapaz de captar ese olor; un olor tal que excede y suple a la vista, que rompe la distancia segura con el otro que establece ese sentido, olor que entra en nosotros con la fuerza de un martillazo; olor que nos implica. Si a estas sensaciones, a este sentido, agregamos cierta ansia revolucionaria de este joven Marx, tal vez alcancemos ya a atisbar las razones de esa llamada de atención. Así, volviendo hacia nuestro objetivo, llegamos a la primera conclusión: la sociología no huele a humano, lo que dice la sociología apenas se siente como un humano, le falta algo que es más que su materialidad.

2 Nos basamos, para este desarrollo, en la introducción a los Manuscritos de economía y filosofía, a cargo de Francisco Rubio Llorente, en la edición de 2003 de Alianza: Madrid.

3 Puede encontrarse una exposición detallada de la sociología de los sentidos desarrollada por Simmel en el artículo de Olga Sabido Ramos (2007: 217 ss). 
Nuestro segundo apunte de carácter teórico nos permite, más allá de la actual -posible- utilidad del materialismo dialéctico, comenzar a aprehender la sociología del cuerpo. En este gesto que venimos describiendo, Marx identifica naturalismo con humanismo, del cual nos dice que "se distingue tanto del idealismo como del materialismo y es, al mismo tiempo, la verdad unificadora de ambos"' (Marx, 2003: 192). Continúa:

El hombre es inmediatamente ser natural [...] como ser natural vivo, está, de una parte, dotado de fuerzas naturales [...]; de otra, como ser natural, corpóreo, sensible, es, como el animal y la planta, un ser paciente, condicionado y limitado [...]. El que el hombre sea un ser corpóreo, con fuerzas naturales, vivo, real, sensible, objetivo, significa que tiene como objeto de su ser, de su exteriorización vital, objetos reales, sensibles, o que sólo en objetos reales, sensibles, puede exteriorizar su vida (Marx, 2003: 192).

Pasando, entonces, del naturalismo al humanismo, la realización en Marx de la filosofía: "El hombre, sin embargo, no es sólo ser natural, sino ser natural humano" (Marx, 2003: 193). Es en este punto, en este descubrimiento, en donde se acaba para Marx la filosofía, pues manifiesta un hartazgo de esa filosofía, como diría también Nietzsche, que se limita a interpretar el mundo sin cambiarlo. Por ello, en adelante será suficiente con la economía política y la historia para comprender e intervenir en el hombre. Economía, pero no esa economía que asienta su creencia, su profesión, en la naturalidad del homo oeconomicus, sino economía como gestión de necesidades, como gestión del hambre ${ }^{4}$. E historia, porque el hombre tiene como la natura-

4 En El reino y la gloria, Giorgio Agamben (2008) desarrolla una etimología de economía que nos mantiene en este enfoque corporal, sensible, en tanto oiko- 
leza un inicio, una vida que se marca en su cuerpo, y en su sociedad.

Con este gesto que venimos repitiendo, Marx traduce supervivencia en economía y decurso de la vida en historia. Asimismo -y éste sería, consideramos, el punto más genuinamente corporal de su enfoque-considera la capacidad sensitiva humana como praxis $\mathrm{y}$, por tanto, como trabajo, transformación de sí mismo (Sánchez, 2001: 328); bajo esta óptica, pues, la corporalidad fundamenta una teoría del humano capaz de transformarse a sí y a su mundo. Se traduce sensibilidad en interpretación enajenante ( $\mathrm{y}$, así también, desenajenante). Estamos aún lejos de Bourdieu; sin embargo, estos breves apuntes empiezan a descubrir las potencialidades epistemológicas de la atención a la condición corporal del ser humano.

Pasemos ahora a algunos aportes posteriores que, en líneas generales, se consideran los primeros pasos genuinos de la sociología del cuerpo. Dejando a un lado, momentáneamente, el desarrollo de la teoría sobre el cuerpo que desde la fenomenología se ha alcanzado ${ }^{5}$, se considera el ensayo de Marcel Mauss, "Técnicas y movimientos corporales (Mauss, 1991)", como el precedente fundamental de lo que significa desarrollar una sociología del cuerpo (ver Bernard, 1985: 174; Douglas, 1988: 94; Le Breton, 2011: 20; Turner, 1989: 31). En este breve ensayo, el antropólogo y sociólogo francés expone el concepto de técnicas corporales, el cual se define como el

nomía es entendido como "gestión de la nutrición", tanto del hogar como de ese otro hogar, el cuerpo (33-9).

5 A este respecto, resultan ineludibles las obras Fenomenología de la percepción, de Maurice Merleau-Ponty, y El segundo sexo, de Simone de Beauvoir, cuya influencia en el auge de la teoría sobre la condición corporal profundizaremos más adelante. 
uso tradicional del cuerpo en diferentes sociedades. Concretamente, se refiere a actos "eficaces" y "tradicionales", es decir, con un recorrido cultural sedimentado. Mauss sostiene que estas técnicas, estas "mejores formas de llevar a cabo" un uso del cuerpo, relacionadas con actos cotidianos del cuerpo, variaban intra e intersocialmente (Mauss, 1991: 344).

Esta clasificación, como puede verse, se encuentra anclada -al menos a simple vista- en la fisiología más básica, en uso social más "sencillo" del cuerpo humano; sin embargo, Mauss la complementa con un abordaje del rendimiento y transmisión de estas mismas técnicas (Mauss, 1991; 345), refiriéndose con ello a la búsqueda de un aprovechamiento óptimo de las fuerzas, es decir, de la adquisición de una habilidad en tanto sentido de la adaptación de estos actos corporales significativos ${ }^{6}$; y al legado e incorporación de las técnicas, ya sea por imposición o imitación. Tratemos, ahora, de resituar este aporte de Mauss en clave marxiana, de forma que podamos sostener que lo que el antropólogo francés desarrolla son algunos de los aspectos de esa praxis transformadora que es la sensibilidad del ser humano, así como su recorrido histórico -o los esbozos de un esquema de clasificación de estas técnicas-, que no es sino el movimiento de esta transformación del mundo y del ser humano a lo largo de su historia.

Como dijimos más arriba, es difícil encontrar, en las raíces de la teoría social, una reflexión siquiera cercana a la de Mauss ${ }^{7}$. Ello, no obstante, no impide que algunos de los con-

6 "Un movimiento se aprende cuando el cuerpo lo ha comprendido, eso es, cuando lo ha incorporado a su 'mundo', y mover su cuerpo es apuntar a través del mismo hacia las cosas" (Merleau-Ponty, 2002: 168).

7 Tal vez Simmel, junto con Marx, constituye una posible excepción a este "canon". Su profundo análisis de la sociología de los sentidos comparte con Mauss la importancia de su aporte, especialmente si tomamos en consideración que en él encontramos el desarrollo de una prefiguración de la fenome- 
ceptos fundamentales de la sociología no puedan ser reinterpretados en concordancia con una teoría social del cuerpo o que, como propone Le Breton, no guarden en sí una sociología del cuerpo de forma implícita (Le Breton, 2002). Demostremos esto brevemente a partir de Weber y Durkheim. En cuanto al primero, tomemos su "desglose" del poder en capacidad de imposición (Macht), poder estructurado (Herrshaft), y disciplina, entendida ésta como una práctica rutinaria, guiada por una obediencia masiva, acrítica y conformadora (Weber, 2010: 162-3). Ha de verse, en la estela weberiana seguida por Foucault hacia la biopolítica, en este esquema mismo, su relación indisociable con los cuerpos afectados. Incluso más, la diferencia entre ambos estriba, entre otros aspectos, en la llamada de atención del filósofo francés sobre la encarnación de estas prácticas disciplinarias, hacia las formas mismas de la encarnación. Fruto de esta diferencia son, como señalamos, el par conceptual anatomopolítica-biopolítica, contenidos en el primer tomo de la Historia de la sexualidad (Foucault, 1987: 168), y que aúnan, en su paso obligado por el cuerpo, ese concepto situado en el entre, al que venimos apuntando. Vemos, pues, cómo esta sociología del cuerpo está en algunos aspectos de la teoría weberiana.

En cuanto a Durkheim, si bien el sociólogo francés no hará menciones explícitas a la condición corporal y a su importancia fundamental en el proceso de socialización -aspecto en el que se centra su sobrino Marcel Mauss-, su caracterización

nología posterior, en tanto fundamenta la construcción social de la sensoriomotricidad humana, así como su carácter constituyente, estructurante. Aquí hemos optado por Mauss por ser más accesible, cuya relación con teorías de importancia para nuestros argumentos, como el habitus en Bourdieu o las tecnologías del yo foucaultianas, es inmediata. Remitimos, en cualquier caso, para profundizar en el costado simmeliano de la sociología del cuerpo, al artículo de Sabido Ramos (ver n. 4). 
del hecho social, más allá de su definición básica ("generales, externos y coactivos"), estará presente -aunque velada- en nuestro desarrollo posterior: "Si todos los corazones vibran al unísono, no es a consecuencia de una concordancia instantánea y preestablecida, sino porque una misma fuerza los mueve en el mismo sentido. Cada uno es arrastrado por todos" (Durkheim, 2001: 41). Fuera de esta cita queda la posibilidad de innovar de una forma no patológica, aunque en las mismas técnicas corporales de Mauss resuene ese "vibrar al unísono", que no deja de ser el empuje mismo de la sensoriomotricidad ontogenética del humano, como aprenderemos con la fenomenología merleaupontiana. No obstante, para poder reaprovechar el pensamiento de Durkheim y resituarlo en una conciencia de la condición corporal, es necesario -así lo entendemos- pensarlo desde el entre. Esta posibilidad está escondida a la vista de todos en las Reglas..., pero el mismo Durkheim, sin embargo, anclará su énfasis en el todo, siempre más (importante) que la suma de las partes: "Aun cuando el hecho social sea debido en parte a nuestra colaboración directa, no por esto cambia de naturaleza" (Durkheim, 2001: 41). El hecho es que cambia, y es gracias a entenderlo desde la ontología marxiana que podemos profundizar en un pensamiento desde el entre en el cual la preeminencia sea nuestra colaboración directa, ya que ésta se debe también a los efectos coactivos externos al cuerpo del individuo, pero que, no obstante, no deja de estar sujeta a la condición sensible -por tanto práctica y transformadora- del humano. Intentar analizar, en un mismo gesto, al individuo y la estructura encarnada, y viceversa; ésa será la forma de comprender sociológicamente nuestra condición corporal.

Turner (1994) señala que este alejamiento de la teoría sociológica de las potencialidades epistemológicas que ofrece 
considerar el cuerpo, encuentra su razón en el fuerte rechazo hacia el determinismo biológico de autores como Spencer o Lombroso, entre otros ${ }^{8}$. Tal alejamiento contribuyó, también, a la "oposición tradicional cultural de occidente entre naturaleza y cultura. Las relaciones sociales pueden incluso concebirse como negación de la naturaleza" (Hirst y Woolley, 1982: 23). Cegar la visión de lo corporal generará, por tanto, una forma incompleta de preguntarse por la sociedad y el ser de lo social; en palabras de Edgar Morin: "La sociología ha desdibujado, borrado al hombre biológico [...]. Han sido recortados todos los puentes entre bios y polis, y anthropos ha quedado dividido en dos" ${ }^{\prime \prime}$. No obstante, otras disciplinas, de las que la sociología es deudora, como la filosofía, la antropología o la psicología, en lugar de cerrarse ante lo biológico justificado en el rechazo al determinismo, han profundizado en ello y en su relación con su objeto de conocimiento, alcanzando muchas veces la argumentación necesaria para desmentir al determinismo. De esta forma, se comprende que los aportes más significativos hacia la teoría social del cuerpo provengan de éstas, antes que de la misma sociología, digamos, canónica. Previo a aproximarnos al interaccionismo simbólico, última

$8 \quad$ Puede consultarse, a este respecto, el ensayo de Stephen Jay Gould, La falsa medida del hombre, en el que lleva su crítica al determinismo biológico hasta los test de ci que, aún hoy, siguen funcionando como criterio discriminante (y determinante).

9 (Morin, 1978). Aunque cierta, la cita no está exenta de una aclaración: en el uso griego de bíos, y en sus formas de denominar lo vivo, se lo encuentra como suplementario de la zoé puramente animal. Bíos no puede contraponerse a polis, porque el concepto de bios es condición de posibilidad de polis, en tanto que se trata de la vida característica de hombres y dioses (ver Agamben, 2010: 9). En cualquier caso, la idea queda bastante clara. Por otra parte, tal precisión etimológica podría poner en duda, y a un tiempo aclarar, las ideas sobre el estado biopolítico foucaultiano, en tanto está más próximo -cada vez más próximo-a una zoepolítica que a una biopolítica. Pero tal precisión, consideramos, está contemplada en el par conceptual que forma en conjunto con la anatomopolítica. 
parada en nuestro recorrido hacia el paradigma sociológico del cuerpo, recuperemos antes algunos de los exponentes ineludibles que "facilitaron" el desarrollo de la posterior teoría del cuerpo, del pensar desde y con los cuerpos.

Comenzamos por la filosofía, resumiendo mucho el recorrido del estatuto del cuerpo en la misma, partiendo de Nietzsche, quien proporcionará las ideas más importantes, puesto que abrirán el camino hacia la atención al cuerpo y, con ello, hacia su recuperación y, en buena medida, hacia la posibilidad de un pensamiento del entre. Esta posibilidad se encuentra contenida, en un sentido general, en su proyecto de inversión del platonismo, lo cual, en la línea de la condición corporal, consiste en romper con la noción "soma = sema", es decir, con la idea del cuerpo como cárcel del alma. Tales ideas se vislumbran ya en el elogio dionisíaco que el filósofo alemán realiza a lo largo de El nacimiento de la tragedia, generando así una ontología estética basada en la contraposición con lo apolíneo (Sloterdijk, 2009). Tal liberación se ejerce bajo la forma de cierto salvajismo, que implica la recuperación de la relación del yo con su parte natural -es decir, su cuerpo intacto-. Ruptura y recuperación que guía la práctica totalidad de la obra nietzscheana, cuyo ejemplo epistemológico más claro situamos en su Genealogía de la moral, de la cual se extrae la conceptualización misma de genealogía, fundamental para el pensamiento posterior sobre el cuerpo. En palabras de Foucault:

El cuerpo, superficie de inscripción de los acontecimientos (mientras el lenguaje los marca y las ideas los disuelven), lugar de disociación del Yo (al que trata de prestar la quimera de una unidad sustancial); volumen en perpetuo desmoronamiento. La genealogía, como análisis de la procedencia está, pues, en la articulación del cuerpo y de la historia [recordemos la sensibilidad 
transformadora marxiana]. De mostrar el cuerpo totalmente impregnado de historia, y la historia arruinando el cuerpo (Foucault, 2008: 32).

Así, gracias a Nietzsche, se deconstruye la idea del humano como animal inacabado pero con memoria y capacidad para autosituarse en un punto de la historia (Turner, 1994: 21); capacidad que debería ejercer, la del principio délfico: "conócete a ti mismo". Animal, el humano, que vive la unidad -ficticia dice Foucault resonando misteriosamente a Descartes- de cuerpo y alma, unidad de esa paciencia que decía Marx, el acaecer de las pasiones, que no se sitúan ni sólo en la mente ni sólo en el cuerpo, sino en el entre.

Desde la antropología, más allá de lo que ya hemos visto con Mauss, Mary Douglas trató en profundidad la encarnación de lo social, también en la línea de la ontología marxista que venimos citando. Sus ideas se resumen en la cita: "Lo que se graba en la carne humana es una imagen de la sociedad" (Douglas, 1991: 134). En su análisis sobre la polución y la intrincada forma de actuación sobre el cuerpo de lo social, el cuerpo expresa la sociedad, de forma que podemos encontrar a través de éste las características de la sociedad de la que procede:

El cuerpo físico es un microcosmos de la sociedad, que se encuentra en el centro de donde emana el poder, que reduce o aumenta sus exigencias en relación directa con la intensificación o el relajamiento de las presiones sociales. [...] Pero al mismo tiempo, el cuerpo físico [...] se conceptúa como opuesto al cuerpo social. Sus exigencias no sólo se subordinan a las exigencias sociales, sino que se consideran contrarias a estas últimas. La distancia que exista entre los dos cuerpos corresponderá al nivel de presión que ejerza la sociedad y a la coherencia de sus clasificaciones (Douglas, 1988: 97). 
Encontramos, en este pasaje, una relación directa con lo apuntado en torno a Nietzsche, así como respecto a la contraposición -aparente- entre naturaleza y sociedad: el cuerpo, en este caso físico-fisiológico, como expresión de una naturaleza supuestamente salvaje, debe ser constreñido al cuerpo social (tal es la doctrina ilustrada de la socialización). Vemos aparecer aquí una idea crucial para los desarrollos posteriores de la teoría del cuerpo: la idea de canon ${ }^{10}$. Douglas hablará únicamente de esta contraposición entre cuerpo fisiológico-salvaje y cuerpo social-canónico-civilizado. Tal contraposición, aunque mantenida, la encontraremos hoy multiplicada, de forma tal que la sociedad sugiere -específicamente la sociedad de consumo- tantos cánones corporales-subjetivos como necesite(mos). Lo que debe verse, por tanto, es la idea de adaptación, de civilización o domesticación del cuerpo a través de cánones corporales, compuesto de técnicas corporales, de disciplinas que funcionan en un esquema de imposición y estructuración de poder (Weber); integración social, entonces, clasificatoria, como puede extraerse, por ejemplo, de Vigilar y castigar, donde Foucault hablará de "mirada normalizadora" (Foucault, 2009: 171). Será en la sociología del consumo donde esta propuesta adquirirá un potencial crítico maduro, del cual La sociedad de consumo, de Jean Baudrillard, da buena cuenta ${ }^{11}$.

Para terminar este breve recorrido nos centraremos en algunos aportes desde el interaccionismo simbólico, con

10 El paralelismo entre canon y habitus será, como veremos, innegable, cfr.: "La hexis corporal es la mitología política realizada, incorporada, convertida en disposición permanente, manera duradera de mantenerse, de hablar, de caminar, y, por ello, de sentir y de pensar" (Bourdieu, 1991: 119).

11 Especialmente, "El objeto de consumo más bello: el cuerpo", en Baudrillard, J. (2009: 155-85). 
especial atención a la perspectiva dramatúrgica de Erving Goffman. Desde sus inicios, con G.H. Mead, esta corriente mantiene la separación cartesiana entre mente, o self, y cuerpo, considerando que éste "puede existir y operar de forma sumamente inteligente sin que haya una persona involucrada en la experiencia" (Mead, 1999: 168). Se profundiza, así, la escisión entre res cogitans y res extensa, distinguiendo que “el cuerpo no se experimenta a sí mismo como un todo, en el sentido en que la persona, en cierto modo, entra en la experiencia de la persona" (Mead, 1999: 168); sin embargo, el mismo Mead, en sus “Ensayos suplementarios”, matizará esta propuesta, sosteniendo una división en el sujeto entre su individualidad biológica y social, en la cual él mismo es capaz de dar cuenta de sí; tal división, agrega, "no se encuentra en planos separados, sino que se unen y separan continuamente y constituyen, en la mayoría de las condiciones, una experiencia que no parece estar dividida por ninguna línea de clivaje" (Mead, 1999: 353). La dificultad para encontrar ese punto pineal se soluciona por una separación y reunión constante y constituyente, no demasiado alejada, si lo pensamos, de la adquisición de habilidad que señalamos con Mauss.

Al focalizarse en la sociedad, Mead sostiene que "el ser humano [...] fisiológicamente, es social en pocas reacciones" (Mead, 1999: 261). La pregunta adecuada, entonces, sería en qué medida, en qué punto, lo social no es necesariamente fisiológico, además de qué puede ser -y querer decir- social y fisiológico, o si se puede sostener racionalmente esa separación más allá de su utilidad conceptual; no obstante, lo que debemos conservar de Mead es que recupera para la sociología el cuestionamiento por la condición corporal, dejando que los cuerpos entren de nuevo en la teoría, habiendo 
superado ya el determinismo biológico, pero todavía no el cartesianismo ${ }^{12}$.

Podríamos decir que la propuesta dramatúrgica de Goffman sí parte del supuesto de que el humano objeto tiene un cuerpo. El estigma, por ejemplo, sirve al sociólogo canadiense para resaltar la significancia psicosocial de los cuerpos, de cómo funciona, a través de ellos y sus estigmas, el sistema clasificatorio que vimos con Mary Douglas. El cuerpo, en la teoría de Goffman, será sólo el pretexto sobre el que se escribe el símbolo en el sistema social de clasificación. En La presentación de la persona en la vida cotidiana, el cuerpo es la parte expuesta del self, un preself sobre el que se juega, en cierta medida de forma involuntaria, pero no de forma inconsciente, el mismo self. La carne es, entonces, un mero soporte, superficie de inscripción, como dijimos con Foucault; el punto de partida de cualquier interacción que se pretenda simbólica. En la medida en que entendemos nuestro cuerpo propio como "estandarte" y superficie de escritura del self, la teoría de Goffman nos proporciona una posibilidad de agencia del cuerpo propio, aprehendido como punto cero $^{13}$ de cualquier

12 Puede decirse, en defensa de Mead, que su referencia a los procesos fisiológicos en los que el self no puede dar cuenta de ellos ni de sí mismo no está en absoluto desencaminada. Drew Leder, en The absent body (1990: 65) conceptualiza esto como "visceralidad" del ser humano, aunque sosteniendo que forma parte de la existencia. Más allá de esto, y de esa "mayor inteligencia" que Mead atribuye a la visceralidad humana, ejemplos como la etapa anal y el control de los esfínteres, desarrollado por Freud, podría poner en jaque parte de la propuesta, en la medida en que una visceralidad y su "mayor inteligencia" es constituida socialmente.

13 "Sólo por su relación empírica con el cuerpo se convierte la conciencia en realmente humana o animal, y sólo por este medio ocupa un lugar en el espacio y en el tiempo de la naturaleza -en el tiempo que se mide físicamente. Acordémonos también de que a) sólo mediante el enlace de la conciencia y el cuerpo en una unidad intuitivo-empírica natural, b) es posible algo así como una comprensión mutua entre los seres animados pertenecientes a un mundo, y que sólo por este medio puede cada sujeto cognoscente encontrarse con el mundo en plenitud, consigo mismo y con otros sujetos, y a la 
intención comunicativa de sí en un marco contextualizado -habitus y campo empiezan a resonar aquí-; así como nos introduce en la exigencia del cuidado de sí en tanto mantenimiento de una intención comunicativa de sí, es decir, de una estabilidad del self continuamente (re)presentado. Le Breton recoge esta idea y la traslada a la sociedad de consumo:

Un mercado en pleno crecimiento renueva todo el tiempo los signos que apunta al mantenimiento y valoración de la apariencia bajo los auspicios de la seducción o de la "comunicación". Ropa, cosméticos, prácticas físicas, etc., forman una constelación de productos codiciados para proporcionar un "palco" en el que el actor social cuida lo que luego permite que se vea a sí mismo como si se tratara de una tarjeta de visita viviente (Le Breton, 2011: 82).

No obstante, la conceptualización que Goffman hace de la estigmatización nos ofrece, acaso, una perspectiva dramatúrgica algo más en consonancia con la situación de la condición corporal en la interacción. En ella, mi cuerpo carga con un preself que no siempre termino de aprender, es decir, de poder dar absoluta cuenta de mí mismo en él, un poco a la manera de la visceralidad a la que nos referimos antes (ver n. 38). Cargamos, como un peso, con un estigma, con un cuerpo plagado de estigmas, de significados de los que debo dar cuenta, incluso a pesar de que no siempre son intencionales y totalmente controlables. Así, bajo este esquema, el cuerpo se mantiene como cárcel del alma, en la medida en que los demás la conforman, con su mirada clasificatoria: “El

vez reconocer en él un mismo mundo circundante, común a él y a todos los demás sujetos" (Husserl, 1985: 126). 
infierno son los demás". El cuerpo, entonces, un posible impedimento a mi intención comunicativa, al self que intento representar; nuestra agencia sobre el mismo es incompleta, ya que se juega en un campo que es de todos. En palabras de Mary Douglas: “El cuerpo, en cuanto medio de expresión, está limitado por el control que sobre él ejerce el sistema social. [...] El control corporal constituye una expresión del control social" (Douglas, 1988: 94). Aunque traumático, y por ello indeseable, este esquema es capaz de dar cuenta de algunos traumas anclados en la corporalidad, especialmente en nuestra sociedad de consumo, como la anorexia, la vigorexia, o el cutting.

Reaparición y auge de la teoría corporalizada

Ahora viene mundus corpus, el mundo como poblamiento proliferante de los lugares (del) cuerpo.

Jean-Luc Nancy, Corpus.

Luego de nuestra breve revisión por los aportes fundamentales de la sociología del cuerpo, pasaremos a incorporar algunos elementos que han dado en una revitalización de la presencia del cuerpo en la teoría, así como del surgimiento mismo de esta sociología. Siguiendo a Turner (1989: 17), algunos de estos elementos son:

Primero que nada, debe reseñarse la importancia crucial de la crítica feminista de la sociedad, en tanto que visibiliza los efectos perniciosos de un orden social sustentado en la diferencia fisiológica; al tiempo que, con esta misma crítica, relativiza los significados culturales del esquema orgánico 
femenino/masculino (mérito, también, que debemos encontrar en las teorías poscolonialistas, así como la misma deconstrucción de la "raza"). A este respecto, es innegable el aporte de Margaret Mead, en Sexo y temperamento en tres sociedades primitivas, prefiguración de la actual teoría queer; $\mathrm{y}$, también, de Simone de Beauvoir y su Segundo sexo, con el que, desde una fenomenología existencialista -elemento, crucial para el desarrollo actual de la teoría corporalizada, junto con el psicoanálisis-, contribuyó a esa deconstrucción y comienzo de resignificación no violenta de la diferencia sexual, con su famosa tesis "no se nace mujer, se llega a serlo" (Beauvoir, 1998: 13). Aun en sí, la lógica epistemológica esencial de esta sociología que estamos exponiendo, es decir, que el cuerpo no esconde predeterminaciones, sus significados y sus efectos son negociables. Así, hacer sociología del cuerpo implica un esfuerzo teórico por comprender el llegar-a-ser-mujer, el llegar a ser cuerpos de los cuerpos. Siguiendo, por último, la estela de la crítica feminista, no podemos dejar de citar la llamada liberación sexual, que seculariza el cuerpo y vuelve más eficaz su mercantilización (Turner, 1989: 18).

Tampoco podemos dejar de lado los avances y nuevas perspectivas en la medicina, que han cambiado por completo nuestra sociedad y nuestro esquema corporal, su funcionamiento y sus límites. Los debates sobre bioética en torno a estos avances, como las nuevas posibilidades de extensión de la vida o la modificación orgánica de los cuerpos, forman parte del interés de la sociología. Debe verse, pues, que no sólo los transplantes rompen en buena medida con cierta mitología acerca de la pureza orgánica, de su unidad indisociable, en tanto que un cuerpo vivo ya no depende de sus "partes" originarias, al igual que la idea de cuerpos y órganos "de reposición"; sin dejar de lado las posibilidades prác- 
ticamente ilimitadas de modificación estética y de cirugía reconstructiva. Por último, debe tenerse en cuenta que estas técnicas y estos avances a los que estamos haciendo referencia han transformado, también, la demografía del mundo, generando -junto con otros elementos socioculturales- una situación de coexistencia generacional sin precedentes.

El otro elemento que señala Turner, y al que venimos haciendo referencia desde el principio, el cual tampoco está exento de cierta relación de retroalimentación con los avances en medicina y la liberación sexual, es el auge y desarrollo de la sociedad de consumo, tal como la entendemos -si es que la entendemos- hoy en día. Baudrillard señala que, en ella, el cuerpo tiene una importancia crucial, que es el objeto de consumo más preciado (tanto por quienes venden cuerpos, como por quienes los compran):

En la panoplia del consumo hay un objeto más bello, más preciado, más brillante que todos los demás hasta cargado de más connotaciones que el automóvil [...]: EL CUERPO. [...] Ha sustituido literalmente al alma en su función moral e ideológica (Baudrillard, 2009: 155).

El cuerpo, en la sociedad de consumo, es un muy exitoso nicho de mercado, cuyos efectos van más allá de la mera apariencia, y que generan un consumo de patrones, de cánones de corporalidad que son, indisociablemente, cánones de subjetividad, patrones de comportamiento. Parte de este elemento es también la expansión del mundo publicitario, de sus técnicas y estrategias. La publicidad, no sólo como ese no-lugar, esa utopía del consumo dedicada a la promoción del logos de los objetos (Baudrillard, 2010: 175), del discurso objetivo en cuanto tal; sino también como paradigma de la exposición 
de los cuerpos consumidores. En la propaganda, el objeto es inseparable de su usuario que le da sentido y que, bajo esta lógica, conforma la ideología de la integración por medio del consumo. Además, la estrategia propagandística nos muestra también el paradigma de la publicidad como tal, es decir, aquello que imbuye a algo como público, que marca el límite de lo que aparece como público frente a lo privado, una profunda contradicción de nuestra sociedad, en la que la consumación es al mismo tiempo el acto más íntimo, pues apunta a la subjetividad; y más público, puesto que también es un método, un paradigma de la integración a lo social más general; en palabras de Baudrillard: "la publicidad no tiene como mira precisamente la 'compulsión' de compra y condicionamiento de los objetos, sino la adhesión al consenso social, cuyo discurso sugiere" (Baudrillard, 2010: 186). En cuanto al cuerpo, debe prestarse atención a las posibilidades de personalización -ya la palabra no podría ser más sintomática- e intercambio simbólico que ofrece el mercado de consumo, desde el arte combinatorio de la moda, hasta la mercantilización de la identidad, aspectos en los cuales el cuerpo es el sustrato fundamental.

No podríamos dejar fuera de estos elementos promotores de este auge de la teoría corporalizada el pensamiento francés contemporáneo, especialmente la figura de Michel Foucault ${ }^{14}$; sus desarrollos conceptuales han proporcionado un puerto seguro al que remitir los nuevos aportes en torno a la corpora-

14 Turner (1989: 61) señala, con bastante acierto, que una sociología del cuerpo, o su posibilidad hoy, es una aplicación de la filosofía foucaultiana. Filosofía que, como la sociología del cuerpo, ha de ser multidisciplinar y minuciosa. Nuestra exposición de las importantes relaciones entre cuerpo y poder, poder corporalizado y corporalizante, son aquí, no obstante, someras y superficiales y requerirían una exposición más profunda que, en el marco de este artículo, no encuentran cabida, no obstante, queremos remitir a la obra de Eagleton, $L a$ estética como ideología, como ejemplo de un profundo desarrollo de este enfoque. 
lidad. Aun siendo un esquema muy específico, la genealogía del biopoder que traza Foucault, ya desde La historia de la locura hasta sus cursos en el Collège de France, han supuesto un nuevo paradigma en la comprensión y análisis de la encarnación de lo social. Asimismo, su atención a las zonas marginales de la organización social, de sus sistemas clasificatorios y sus consecuencias, como sus potentes estudios sobre la locura, la medicina, el sistema penitenciario o educativo, entre otros, hacen notar la estrecha relación entre teoría social y atención a la socialización o encarnación de los mismos. Con ello, expande nuestra comprensión sobre el funcionamiento del biopoder, estatal o no, llevándolo a este ámbito en el que se sitúa el capitalismo de consumo actual, que promueve y cuida la vida, que hace vivir y consumir, cuya máxima expresión sería el estado de Bienestar.

Será bajo este marco que los análisis desde la sociología del cuerpo en general, pero con la especificidad del consumo y la publicidad, adquirirán una mayor profundidad y potencia crítica, la cual ilumina el camino a posibles soluciones $-\mathrm{O}$, al menos, a la posible localización de las mismas-, todo lo cual no sería posible sin esa atención básica al hecho mismo de la encarnación, de la gravación de lo social en los cuerpos, por usar las palabras de Mary Douglas. Seguimos, como se ve, la huella del materialismo marxista que, acaso en su momento, se "perdió" en la economía política, pero que sigue presente en los caminos abiertos por la llamada de atención a nuestra condición corporal sensible. Marco, junto con el de biopoder, que da sentido a las prácticas publicitarias y de consumo como verdaderas técnicas (corporales) de control social, de conformación de lo social y sus mentes, sus cuerpos. Tal vez, también, inversión de la condena platónica del cuerpo: 
El hombre de que se nos habla y que se nos invita a liberar es ya en sí el efecto de un sometimiento mucho más profundo que él mismo. Un "alma" lo habita y lo conduce a la existencia, que es una pieza en el dominio que el poder ejerce sobre el cuerpo. El alma, efecto e instrumento de una anatomía política; el alma, prisión del cuerpo (Foucault, 2009: 30).

Resuenan en estas palabras las de Marx, las de Mauss, las de Douglas. Es gracias a su contundencia como alcanzamos a comprender el interés que suscitaron, suficiente como para reabrir el interés en la corporalidad, en su importancia.

Para terminar, este auge que venimos comentando aparecería incompleto sin la debida mención hacia la globalización y las nuevas tecnologías. Nos interesa resaltar, aunque no de forma exclusiva, los cambios que han originado estos dos elementos en la forma de entender, de construir, nuestro cuerpo. Como por ejemplo la idea de universalidad, de igualdad casi preciudadana, promulgada en la Declaración Universal de los Derechos Humanos, que cambia y acaso mejora el estatuto de la igualdad humana anclándola, sin lugar a dudas, en su fisiología más esencial, de mínimos (o nuda vida, por usar las palabras de Agamben), ideas que transforman la manera de entender y juzgar los cuerpos, partes ahora de un planeta, de un mundo, y no ya de una nación. Cuerpos cosmopolitas que no se entienden fuera del marco biopolítico capitalista. Cuerpos que generan nuevas fronteras, que van más allá de la nacionalidad, que generan nuevos apartheids. Por su parte, las nuevas tecnologías y modos de comunicación e información "evolucionan" nuestra manera de entendernos como seres humanos, que expanden los límites de la interacción más allá de cualquier frontera. A ello se suma la expansión de la virtualidad, de cierto "virtualismo", de 
cuerpos virtuales, que encontramos no sólo en el ocio, sino en todas las tecnologías de telepresencia (y ausencia).

Como vemos, todos son elementos que forman un caldo de cultivo para un pensamiento y una crítica social desde la corporalidad, en la medida en que todos ellos afectan a la noción misma de corporalidad, a sus sentidos y sus potencialidades. En el siguiente apartado intentaremos llevar nuestra discusión a la teoría sociológica contemporánea, acercándonos a una unión entre lo que venimos proponiendo y el par conceptual desarrollado por Bourdieu: habitus y campo.

Habitus, cuerpo y campo

Podríamos [...] decir que las piernas y los brazos están llenos de imperativos adormecidos. Y no acabaríamos nunca de enumerar los valores hechos cuerpo, mediante la transubstanciación que efectúa la persuasión clandestina de una pedagogía implícita, capaz de inculcar toda una cosmología, una ética, una metafísica, una política, a través de exhortaciones tan insignificantes como "mantente derecho".

Pierre Bourdieu, El sentido práctico.

El objetivo de este apartado es seguir el recorrido iniciado en el primer epígrafe, intentaremos contextualizar la teoría del habitus y el campo de Bourdieu en la sociología del cuerpo que he venido delineando. Para ello, partiré desde el concepto de técnicas corporales de Mauss, antes expuesto, y al que debo agregar las consideraciones desde la fenomenología de Merleau-Ponty, en tanto consideran el cuerpo como lugar primordial de la apropiación del mundo y del ser (Merleau- 
Ponty, 2002: 184), la apropiación genuina; de forma tal que comprendamos el verdadero alcance de estas técnicas que exceden la mera manifestación de la socialización, hasta la forma misma de constitución del sujeto, de lo que sea que es un sujeto. Tal posibilidad está contenida en el concepto desarrollado por Foucault, las tecnologías del yo, las cuales:

[...] permiten a los individuos efectuar, por cuenta propia o con la ayuda de otros, cierto número de operaciones sobre su cuerpo y su alma [...], o cualquier forma de ser, obteniendo así una transformación de sí mismos, con el fin de alcanzar un cierto estado de felicidad, pureza, sabiduría o inmortalidad (Foucault, 2010: 48).

Son técnicas de la ocupación de sí mismo, que abarcan un conocimiento de uno mismo y un cuidado de sí (Foucault, 2010: 50). Comprenderemos mejor este rodeo por la técnica con las reflexiones de Gadamer acerca de la Ética a Nicómaco. Aristóteles considera como elemento específicamente humano la capacidad de ser ético ${ }^{15}$, refiriéndose a ella como técnica similar a la del artesano. Tal capacidad implica, dice Gadamer, una cierta habilidad interpretativa, una hermenéutica ${ }^{16}$, en la que el hombre debe enfrentar su situación concreta a la luz de un conocimiento general sobre ética. El sujeto ejerce una reflexividad que es una contextualización (y un "sujetamiento"): ha de comprender la situación y comprenderse a

15 En la base de esta doctrina encontramos una identificación entre virtud y saber. Es significativo que Aristóteles considere, como en las técnicas corporales, que la repetición y el hábito son indispensables para alcanzar la virtud en la aplicación del conocimiento ético. Tal hábito, sucesión de repeticiones, es inseparable, también, de una madurez, de una edad (Gadamer, 2011: 82).

16 No olvidemos que una de las acepciones de interpretación está relacionada con la dramaturgia, con lo cual nos mantenemos en la estela de la perspectiva dramatúrgica (y del estigma) trazada por Goffman. 
sí en ella, para que de esa conjugación se derive un juicio y una práctica. Se trata, apunta Gadamer, de un conocimiento general, externo, que dirige la acción pero no la determina (Gadamer, 2011: 86). La ética, por tanto, no es una técnica exactamente igual que la del artesano, que es más bien un conocimiento dirigido al objeto; sino que se trata, como dijimos, de una hermenéutica: la aplicación ética es inseparable de la proyección de sí (con su consecuente y "previo" conocimiento de sí) en el contexto de sus posibilidades de ser de sí. Gracias a este camino abierto podemos distinguir la extensión de los conceptos de Mauss y Foucault: en el primero, sí, nos movemos en el ámbito de la técnica del artesano; en el segundo, nos encontramos que es más que técnica, que es una hermenéutica del sujeto, en la que él mismo se constituye y reconstituye continuamente.

Tal será la estructura de relaciones imbricada en el par conceptual desarrollado por Pierre Bourdieu, el habitus y el campo. Desde su misma definición se destaca su atención a la condición corporal:

Historia incorporada, naturalizada y, por ello, olvidada como tal historia, el habitus es la presencia activa de todo el pasado del que es producto: es lo que proporciona a las prácticas su independencia relativa en relación a las determinaciones exteriores del presente inmediato. [...] Espontaneidad sin consciencia ni voluntad, el habitus se opone por igual a la necesidad mecánica y a la libertad reflexiva, a las cosas sin historia de las teorías mecanicistas y a los sujetos "sin inercia" de las teorías racionalistas (Bourdieu, 1991: 98).

Lo que encontramos en esta cita es una traducción del juego hermenéutico a los términos del habitus, como ese con- 
junto de disposiciones sedimentadas históricamente (a esto apuntaba, en su genealogía, Nietzsche), que funcionan como marcos de interpretación de sí de un sujeto en su contexto, su campo, el cual demanda dichos habitus, al tiempo que los pone en juego, abriendo la posibilidad del cambio. Por ello, la realización del habitus es una hermenéutica en la que el sujeto se sujeta, puesto que debe encontrarse a sí en ella, pero que, en su búsqueda de sí puede llegar a nuevas interpretaciones, nuevas actuaciones. El sujeto queda, así, suspendido en un entre que es como su cuerpo, a medio camino entre objetivo y subjetivo, o mejor, simultáneamente subjetivo y objetivo: "Todo sucede como si el habitus fabricara coherencia y necesidad a partir del accidente y de la contingencia; como si consiguiera unificar los efectos de la necesidad social sufrida desde la infancia, a través de las condiciones materiales de existencia" (Bourdieu, 1991: 134). Quedamos, por tanto, a un paso de la aplicación de este enfoque corporal a la sociología del consumo que, no obstante, encontramos ya realizado en La distinción:

El gusto, una cultura de clase entregada a la naturaleza, lo que significa encarnada, ayuda a dar forma a la clase del cuerpo. Se trata de un principio incorporado de clasificación que gobierna todas las formas de incorporación, eligiendo y modificando todo lo que el cuerpo infiere y digiere y asimila, fisiológica y psicológicamente. Ello lleva al cuerpo a ser la materialización indiscutible del gusto de clase (Bourdieu, 1984: 190).

Ante esto, la sociedad de consumo queda delineada como aquel campo en el que se juegan estos habitus, en los que media la publicidad como sugerencia pero, también, como juzgado de mi adecuación o no a los habitus que me co- 
rresponden si deseo formar parte de sus mecanismos de integración. En caso contrario, nos resta la hysteresis, la denominación del estigma de la inadecuación de mi habitus al campo general del biopoder.

Conclusiones

Detrás de tus pensamientos y de tus sentimientos existe un señor más poderoso, un sabio desconocido: se llama el ser.

Vive en tu cuerpo; es tu cuerpo. Hay más razón en tu cuerpo que en la mejor sabiduría.

Friedrich Nietzsche, "De los despreciadores del cuerpo", Así habló Zaratustra.

Al comenzar este artículo diserté acerca de la posibilidad de considerar el cuerpo, dentro de la sociología, como una potente herramienta epistemológica, ello nos exige intentar una definición hacia este objetivo. Hemos visto que el cuerpo es capaz de funcionar como un punto de partida que rompe con la oposición sujeto-objeto, pasado-presente, facilitando así un abordaje dinámico de la realidad social (frente al abordaje estático de la sociología clásica). El cuerpo expone, en un único gesto, lo individual de lo social y la individuación, la encarnación, de lo social como una puesta en juego de los habitus o cánones corporales. De esta forma, el cuerpo se sitúa en el punto cero de la constitución de lo social mismo. Asimismo, en atención a fenómenos de actualidad, como la anorexia, el body-hacking, la vejez y la masificación, al igual que la sexualidad y la globalización, el cuerpo, así considerado, nos ofrece un punto de partida epistemológico capaz de captar la multidimensionalidad de estos fenómenos. 
Vivimos en un momento que demanda una especial atención a nuestras corporalidades, un momento en el que las técnicas del marketing encuentran en él un potente nicho de mercado, que permiten que sus efectos pasen inadverti$\operatorname{dos}^{17}$. El cuerpo expresa la existencia humana, sus miserias, sus placeres, sus historias, como tal, es una fuente genuina de información sociológica. Los datos sociales que nos proporciona van más allá de su nacimiento, su muerte, sus enfermedades, nos informa de sus deseos y de sus penas, del porqué de ellas, de por qué no poder tener algo, o tenerlo, cambia nuestro humor; del por qué algunas cargan un estigma que otros no. Datos que siempre hablan de nuestra actualidad y simultáneamente de nuestra historia, datos que nos sitúan, que hablan de nosotros.

\section{Bibliografía}

Agamben, G. (2008). El reino y la gloria. Una genealogía teológica de la economía y del gobierno. Traducción de Flavia Costa, Edgardo Castro y Meredes Ruvituso, Adriana Hidalgo editora.

Agamben, G. (2010). Homo sacer I. Valencia: Pre-textos. Baudrillard, J. (2009). La sociedad de consumo. Madrid: Siglo XXI. Baudrillard, J. (2010). El sistema de los objetos. Madrid: Siglo XXI.

17 Uno de los ejemplos que más llama la atención es el denominado neuromarketing, cuyo objetivo es, precisamente, esta subliminalidad. En palabras de Martin Lindström, uno de sus promotores: "Las marcas son emociones que transmitimos a un producto, no es algo que puedas tocar o sentir, está sólo en nuestra mente, y por eso el neuromárketing está teniendo un éxito tan rápido, porque la industria estaba desesperada por descubrir las formas de comprender la mente irracional, ya que constituye un importantísimo campo de batalla en lo que concierne a la implantación del valor de marca en nuestros cerebros" (citado en http:/ / living-marketing.blogspot.com. es/2012/12/previsiblemente-irracionales_19.html). 
Beauvoir, S. (1998). El segundo sexo II: la experiencia vivida. Madrid: Cátedra.

Bernard, M. (1985). El cuerpo. Barcelona: Paidós.

Bourdieu, P. (1991). El sentido práctico. Madrid: Taurus.

Bourdieu, P. (1984). Distinction. A social critique of the judgement of taste. Cambridge: Harvard University Press.

Douglas, M. (1988). Símbolos naturales. Madrid: Alianza.

Douglas, M. (1991). Pureza y peligro. Madrid: Alianza.

Durkheim, E. (2001). Las reglas del método sociológico. Madrid: Akal.

Engels, F. y Marx, K. (1994). La ideología alemana. Valencia: Universidad de Valencia.

Foucault, M. (1987). Historia de la sexualidad I. La voluntad de saber. Madrid: Siglo XXI.

Foucault, M. (2008). Nietzsche, la genealogía, la historia, Valencia: Pre-textos.

Foucault, M. (2009). Vigilar y castigar. Madrid: Siglo XXI.

Foucault, M. (2010). Tecnologías del yo. Barcelona: Paidós.

Gadamer, H.G. (2011). El problema de la conciencia histórica. Madrid: Tecnos.

Goffman, E. (1987). La presentación de la persona en la vida cotidiana. Madrid: Amorrortu.

Goffman, E. (1993). Estigma. La identidad deteriorada. Buenos Aires: Amorrortu.

Hirst, P. y Woolley, P. (1982). Social Relations and Human Attributes. Londres: Tavistock.

Husserl, E. (1985). Ideas relativas a una fenomenología pura y una filosofía fenomenológica. Madrid: FCE.

Le Breton, D. (2002). Antropología del cuerpo y modernidad. Buenos Aires: Nueva Visión.

Le Breton, D. (2011). La sociología del cuerpo. Buenos Aires: Nueva Visión. 
Leder, D. (1990). The Absent Body. Chicago: The University of Chicago Press.

Marx, K. (2003). Manuscritos de economía y filosofía. Madrid: Alianza.

Mauss, M. (1991). Sociología y antropología. Madrid: Tecnos. Mead, G. (1999). Espíritu, persona y sociedad desde el punto de vista del conductismo social. Barcelona: Paidós.

Mead, M. (2006). Sexo y temperamento en tres sociedades primitivas. Barcelona: Paidós.

Merleau-Ponty, M. (2002). La fenomenología de la percepción. Madrid: Editora Nacional.

Morin, E. (1978). Diario de California. Madrid: Fundamentos.

Nancy, J.-L. (2003). Corpus. Madrid: Arena libros.

Nietzsche, F. (2008). Así hablaba Zaratustra. Madrid: EDAF.

Sabido Ramos, O. (2007). El cuerpo y sus trazos sociales. Una perspectiva desde la sociología. En Zabludovsky, G. (coord.), Sociología y cambio conceptual. México, D.F.: Siglo XXI, pp. 208-47.

Sánchez Meca, D. (2001). Teoría del conocimiento. Madrid: Dykinson.

Sloterdijk, P. (2009). El pensador en escena. El materialismo de Nietzsche. Valencia: Pre-textos.

Turner, B. (1989). El cuerpo y la sociedad. México, D.F.: FCE.

Turner, B. (1994). Los avances recientes en la teoría del cuerpo. REIS, $68,11-39$.

Weber, M. (2010). Conceptos sociológicos fundamentales. Madrid: Alianza. 


\section{Resumen}

El objetivo de este texto es presentar la sociología del cuerpo como un marco analítico conceptual necesario para la teoría sociológica, puesto que desde él se dimensionan adecuadamente realidades sociales habitualmente descuidadas por la teoría general. Así, se plantea una definición epistemológica del cuerpo surgida de las distintas aproximaciones históricas que se han llevado a cabo desde la teoría hacia las realidades de los cuerpos. Problemáticas como el género, la discapacidad, la ética o el consumo (entre otras) adquieren una mayor fortaleza y coherencia explicativa al ser abordadas desde la sociología del cuerpo. Se revisan los aportes de autores como Mauss, Foucault, Douglas o Bourdieu, así como de paradigmas ya asentados en la teoría sociológica, como el interaccionismo simbólico; de cara a la exposición de las claves teóricas de esta sociología que no se agota en la mera descripción, sino que busca y tematiza las raíces de lo social, de su funcionamiento, en lo más profundo de las personas.

Palabras clave: cuerpo-consumo-hermenéutica-socialización-subjetividad-epistemología.

\section{Abstract}

The aim of this paper is to present Sociology of the body as a required conceptual framework for general social theory, since it can articulate social realities usually neglected in general Sociology. Thus, from the various historial aproaches that gave voice to this realities, arises an epistemologycal definition of the human body, that aims to properly size issues as gender, disability, consumerism, ethics, and so on. Here we examine the contributions of authors as Mauss, Foucault, 
Douglas or Bourdieu, as well as classic and already established paradigms in social theory, and most precisely, symbolic interactionism.

Keywords: Body-Consumerism-Hermeneutics-Socialization-Subjectivity-Epistemology. 